\title{
The flexible structure of the K24S28 region of Leucine-Rich Amelogenin Protein (LRAP) bound to apatites as a function of surface type, calcium, mutation, and ionic strength
}

\author{
Jun-xia Lu, Sarah D. Burton, Yimin S. Xu, Garry W. Buchko and Wendy J. Shaw*
}

Fundamental and Computational Sciences Directorate, Pacific Northwest National Laboratory, Richland, WA, USA

Edited by:

Megan Pugach-Gordon, The Forsyth Insitute, USA

\section{Reviewed by:}

Javier Catón, King's College London, UK

Seo-Young Kwak, The Forsyth Institute, USA

\section{*Correspondence:}

Wendy J. Shaw, Fundamental and Computational Sciences Directorate,

Pacific Northwest National

Laboratory, Richland, WA, USA

e-mail:wendy.shaw@pnnl.gov
Leucine-Rich Amelogenin Protein (LRAP) is a member of the amelogenin family of biomineralization proteins, proteins which play a critical role in enamel formation. Recent studies have revealed the structure and orientation of the $\mathrm{N}$ - and $\mathrm{C}$-terminus of LRAP bound to hydroxyapatite (HAP), a surface used as an analog of enamel. The structure of one region, K24 to S28, was found to be sensitive to phosphorylation of S16, the only naturally observed site of serine phosphorylation in LRAP, suggesting that K24S28 may sit at a key region of structural flexibility and play a role in the protein's function. In this work, we investigated the sensitivity of the structure and orientation of this region when bound to HAP as a function of several factors which may vary during enamel formation to influence structure: the ionic strength $(0.05,0.15,0.2 \mathrm{M})$, the calcium concentration $(0.07$ and $0.4 \mathrm{mM})$, and the surface to which it is binding [HAP and carbonated apatite (CAP), a more direct mimic of enamel]. A naturally occurring mutation found in amelogenin (T21I) was also investigated. The structure in the K24S28 region of the protein was found to be sensitive to these conditions, with the CAP surface and excess $\mathrm{Ca}^{2+}(8: 1$ $\left[\mathrm{Ca}^{2+}\right]$ :[LRAP-K24S28(+P)]) resulting in a tighter helix, while low ionic strength relaxed the helical structure. Higher ionic strength and the point mutation did not result in any structural change in this region. The distance of the backbone of K24 from the surface was most sensitive to excess $\mathrm{Ca}^{2+}$ and in the T21I-mutation. Collectively, these data suggest that phosphorylated LRAP is able to accommodate structural changes while maintaining its interaction with the surface, and provides further evidence of the structural sensitivity of the K24S28 region, a sensitivity that may contribute to function in biomineralization.

Keywords: amelogenin, LRAP, secondary structure, biomineralization protein, solid state NMR

\section{INTRODUCTION}

Leucine-Rich Amelogenin Protein (LRAP) (Gibson et al., 1991) is a member of the amelogenin family of proteins, proteins which are known to be essential in the formation of enamel (Simmer and Fincham, 1995; Fincham et al., 1999; Margolis et al., 2006). The 59-residue protein is a splice-variant of full-length amelogenin and contains only the $\mathrm{N}$ - and the $\mathrm{C}$-terminus (Gibson et al., 1991), regions associated with protein-protein and protein-HAP interactions in the full-length protein (Simmer and Fincham, 1995; Margolis et al., 2006). The role of LRAP in enamel formation is unclear, but it has been demonstrated to control both crystal organization in vivo (Gibson et al., 2008) and crystal width in vitro (Ravindranath et al., 2007), and may also serve a protein-regulating role (Stahl et al., 2013).

Structural studies of amelogenin have been challenged due to their self-assembly into quaternary structures containing 20-100 monomers called nanospheres (Fincham et al., 1994; MoradianOldak et al., 1994, 1995). These complexes, which form under many different conditions, are $500-1000 \mathrm{kDa}$ in size and have never been crystallized, making structure determination using traditional solution-state NMR and X-ray diffraction (XRD) methods difficult. Solution studies at low $\mathrm{pH}$, a condition that stabilizes the monomeric state, suggest amelogenin adopts few elements of canonical secondary structure, characteristic of intrinsically disordered proteins (Tompa, 2002; Uversky, 2002), making detailed structural analysis more complicated (Delak et al., 2009; Zhang et al., 2011; Buchko et al., 2013).

In recent years, solid state NMR (SSNMR) techniques have been extremely valuable for the quantitative structural characterization of biomineralization proteins in general (Drobny et al., 2002, 2003, 2006; Stayton et al., 2003; Goobes et al., 2007), and amelogenins in particular (Shaw et al., 2004, 2008; Shaw and Ferris, 2008; Masica et al., 2011; Lu et al., 2013a,b). Studying proteins bound to surfaces is inherently a solid state problem, and with the use of isotopic labels, SSNMR enables the sitespecific investigation of structure, protein-surface interactions, and dynamics. Using such methods, LRAP has been extensively studied bound to hydroxyapatite (HAP), an analog for enamel which is described as carbonated apaptite (Simmer and Fincham, 1995; Fincham et al., 1999; Margolis et al., 2006), in order to identify structural features which may play important roles in binding to enamel (Shaw et al., 2004, 2008; Shaw and Ferris, 2008; Masica 
et al., 2011; Lu et al., 2013a,b). Many studies show that LRAP is a good model for the full-length protein (Moradian-Oldak et al., 1998b; Moradian-Oldak, 2001; Shaw et al., 2004, 2008; Le et al., 2006; Tarasevich et al., 2010) with the added advantage that its smaller size (59 residues) allows the incorporation of site-specific isotopic labels via solid phase peptide synthesis (Shaw et al., 2004, 2008; Shaw and Ferris, 2008; Masica et al., 2011; Lu et al., 2013b; Tarasevich et al., 2013). This has enabled quantitative structural studies of LRAP bound to HAP, providing much of the existing molecular level details of amelogenin's interactions with solid surfaces (Shaw et al., 2004, 2008; Shaw and Ferris, 2008; Masica et al., 2011; Lu et al., 2013b; Tarasevich et al., 2013).

Quantitative structural, dynamic, and orientation studies of LRAP bound to HAP include the following regions in the Cand the N-terminus: G8-Y12, L15-V19, V19-L23, K24-S28, L42A46, A49-T53, and K54-V58 (Shaw et al., 2004, 2008; Shaw and Ferris, 2008; Masica et al., 2011; Lu et al., 2013b). In these pairs the first residue corresponds to a ${ }^{13} \mathrm{C}$-backbone carbonyl and the second a ${ }^{15} \mathrm{~N}$-backbone amide. Collectively, the data on these LRAP samples bound to HAP represent the most comprehensive study of a biomineralization protein to date. In general, the C-terminus was found to be largely disordered and oriented close enough to the surface to influence mineral growth (5.8-8.0 $\AA$ ), but at the same time is highly dynamic, suggesting that other regions of the protein may also be close enough to the HAP surface to stabilize interactions (Shaw et al., 2004, 2008; Shaw and Ferris, 2008). Investigations in the N-terminus revealed that this region contained much more helical content. The N-terminus was also similar in distance from or further from the HAP surface than the C-terminus depending on the phosphorylation state, 7.0-9.0 $\AA$ for $\operatorname{LRAP}(-\mathrm{P})$ and 5.3-7.0 $\AA$ for $\operatorname{LRAP}(+\mathrm{P})$, still close enough to the HAP surface in both cases to influence mineral growth. The variable distance suggests that in addition to interacting with HAP, the N-terminus may serve a second function such as facilitating protein-protein interactions (Masica et al., 2011). Neutron reflectivity studies bound to $\mathrm{COOH}-\mathrm{SAMs}$ were also consistent with the $\mathrm{N}$ - and C-terminus of LRAP interacting with the surface (Tarasevich et al., 2013).

The only naturally observed site of serine phosphorylation in LRAP is at serine 16. To investigate the potential structural and functional implications of S16 phosphorylation, we recently completed SSNMR structural studies on the N-terminus of S16 phosphorylated LRAP and compared them to unphosphorylated LRAP. Using samples with pairs of site-specific labels (first residue a ${ }^{13} \mathrm{C}$-backbone carbonyl and the second ${ }^{15} \mathrm{~N}$-backbone amide), three regions covering the N-terminus, L15V19, V19L23, and $\mathrm{K} 24 \mathrm{~S} 28$, were studied bound to HAP as a function of solution condition. While some structural and dynamic variations in the L15-L23 region were noted, the most significant differences were observed in the K24S28 region (Lu et al., 2013b) a site 16 residues away from the phosphorylation. The sensitivity of the structure and dynamics of the $\mathrm{K} 24 \mathrm{~S} 28$ region to phosphorylation suggests that this may be a site with a potentially important role in biomineralization. Indeed, previous modeling studies suggest that $\mathrm{K} 24$ is a point at which the protein turns from the surface (Masica et al., 2011). In this work, we more fully investigate the structural and dynamic consequences on S16 phosphorylated LRAP by factors that may vary during enamel development: ionic strength $(0.05,0.15$, and $0.2 \mathrm{M}), \mathrm{Ca}^{2+}$ concentration, and surface identity [HAP vs. carbonated apatite (CAP)]. A naturally occurring mutation found in full-length amelogenin (T21I) (Ravassipour et al., 2000) which results in malformed enamel was also investigated, due to its proximity to the K24S28 region. The implications of our results on the development of enamel will be considered.

\section{EXPERIMENTAL METHODS \\ MATERIALS}

Labeled amino acids were purchased from Cambridge Isotopes (Andover, MA). Fmoc-protected labeled amino acids were prepared as previously described (Shaw et al., 2008) using standard procedures (Carpino and Han, 1972; Wiejak et al., 1999). The HAP $\left(90 \mathrm{~m}^{2} / \mathrm{g}\right)$ used for binding was made and characterized according to literature preparation (Ebrahimpour et al., $1993)$ and stored as a slurry $(28.9 \mathrm{mg} / \mathrm{mL})$ to maintain the high surface area.

\section{CARBONATED APAPTITE (CAP) SYNTHESIS AND CHARACTERIZATION}

Solutions of calcium nitrate $(1.18 \mathrm{~g}$ in $20 \mathrm{~mL}$ water) and sodium dihydrogen phosphate $(0.41 \mathrm{~g}$ in $20 \mathrm{~mL}$ water) contained in dropping funnels were added simultaneously and dropwise at a rate of ca. 1 drop per second to a solution of sodium hydrogen carbonate $(0.13 \mathrm{~g}$ in $20 \mathrm{~mL})$ previously heated to $60 \pm 5^{\circ} \mathrm{C}$. The $\mathrm{NaHCO}_{3}$ solution was contained in a three-neck round bottom flask and was stirred magnetically. The $\mathrm{pH}$ was maintained at nine throughout the addition. When the addition was complete, the mixture was maintained at $\mathrm{pH}=9$ with stirring at $60 \pm 5^{\circ} \mathrm{C}$ for $2 \mathrm{~h}$. After the mixture cooled to room temperature it was vacuum filtered using a Büchner funnel and the residue was washed four times with distilled water. The product ( $0.91 \mathrm{~g}, 65 \%$ yield) was dried in a $120^{\circ} \mathrm{C}$ oven for $24 \mathrm{~h}$. Powder XRD showed no evidence of calcium carbonate or other impurities. The XRD line pattern of the product was in good agreement with PDF-00001-1008 HAP. The percent carbonate (5.2\%) was determined by Galbraith Laboratories, Knoxville, TN by combustion in oxygen at $1000^{\circ} \mathrm{C}$; the surface area was determined by the BET method to be $172 \mathrm{~m}^{2} / \mathrm{g}$. All reagents were ACS reagent grade and distilled water was used throughout.

\section{PROTEIN SYNTHESIS AND PURIFICATION}

Site-specifically labeled LRAP-K24S28(+P) was prepared by solid phase peptide synthesis using Fmoc-chemistry by the Protein Chemistry Technology Center, University of Texas, (Dallas, TX). Isotopically labeled backbone carbonyl carbon at $\mathrm{K} 24\left({ }^{13} \mathrm{C}^{\prime}\right)$ and amide nitrogen at $\mathrm{S} 28\left({ }^{15} \mathrm{~N}\right)$ were introduced in the $i$ and $i+4$ positions, respectively (Figure 1). The T21I-mutant is LRAP$\mathrm{K} 24 \mathrm{~S} 28(+\mathrm{P})$ prepared with the substitution of threonine at position 21 with an isoleucine. The proteins were purified by reverse phase HPLC using: buffer A, $0.1 \%$ trifluoroacetic acid in water; buffer B, $0.1 \%$ trifluoroacetic acid in acetonitrile. Both proteins eluted at $54 \%$ B. Mass spectroscopy was used to characterize the purity and molecular weight of the proteins. After purification, proteins were lyophilized, and stored until ready for use. 


\section{PROTEIN SOLUTIONS}

LRAP-K24S28(+P) was bound to HAP under three different conditions and bound to CAP under the "standard condition," while the T21I-mutant was bound to HAP under the "standard condition" (Table 1). The "standard condition" is defined as $\mathrm{pH}=7.4$, $I S=0.15 \mathrm{M}$, and $326 \mu \mathrm{g} / \mathrm{mL}(0.047 \mathrm{mM})$ LRAP. The solution for the standard conditions samples was prepared as follows: a buffer saturated with respect to HAP (Saturated Calcium PhosphateSCP; the resulting solution has a $\mathrm{Ca}^{2+}$ concentration of $0.07 \mathrm{mM}$ ) was prepared by stirring excess HAP in a $0.15 \mathrm{M} \mathrm{NaCl}(\mathrm{pH} 7.4)$ solution, maintaining $\mathrm{pH}$. After $12-24 \mathrm{~h}$, the undissolved HAP was filtered $(0.22 \mu \mathrm{m}$, Isopore, Millipore). LRAP (16.8 mg) was then dissolved into $50 \mathrm{~mL}$ of SCP $(326 \mu \mathrm{g} / \mathrm{mL} ; 0.047 \mathrm{mM})$ and the $\mathrm{pH}$ adjusted to 7.4. For solutions with different ionic strengths, the same procedure was followed, but the $\mathrm{NaCl}$ concentration was adjusted to obtain the desired ionic strength $(0.05$ or $0.2 \mathrm{M})$. For the solution with eight-times excess calcium added relative to the LRAP concentration, the same procedure was followed, but $\mathrm{CaCl}_{2}$ was added to obtain $0.4 \mathrm{mM}\left[\mathrm{Ca}^{2+}\right]$, providing a $\left[\mathrm{Ca}^{2+}\right]$ :[LRAP-K24S28(+P)] of 8:1.

\section{PROTEIN ADSORPTION TO HAP OR CAP}

The HAP or CAP was prepared for protein adsorption by washing $54.3 \mathrm{mg}$ of HAP or CAP three times with $10 \mathrm{~mL}$ of SCP immediately before adding it to one of the above protein solutions. The mixture was stirred for $3 \mathrm{~h}$ at room temperature, centrifuged, and the LRAP-HAP or LRAP-CAP complex washed three times with $5 \mathrm{~mL}$ SCP to remove non-specifically bound protein. The amount of protein bound to HAP or CAP was determined by measuring

MPLPPHPGSP GYINLSYEVL TPLKWYQSMI RQPYPSYGYE PMGGWLHHQI
IPVLSQQHPP SHTLQPHHHL PVVPAQQPVA PQQPMMPVPG HHSMTPTQHH
QPNIPPSAQQ PFQQPFQPQA IPPQSHQPMQ PQSPLHPMQP LAPQPPLPPL
FSMQPLSPIL PELPLEAWPA TDKTKREEVD
FIGURE 1 I Murine amelogenin amino acid sequence. The primary
amino acid sequence of murine amelogenin with the basic and acidic
residues colored blue and red, respectively. The splice-variant LRAP is
Composed of the N-terminal 33 and C-terminal 26 residues, shaded gray.
Both full-length amelogenin and LRAP are post-translationally modified by
side chain phosphorylation of S16, shaded yellow. The isotopic labels at
specific atomic locations and residues are shown with the arrows: K24
$\left({ }^{13} \mathrm{C}^{\prime}\right.$ ) and S28 ( $\left.{ }^{15} \mathrm{~N}\right)$. In the T21I-mutant the threonine at position 21 is
replaced with an isoleucine.

Table 1 | Sample conditions studied and their binding efficiency.

\begin{tabular}{lc}
\hline Condition & Binding ( $\mathbf{4} \%)$ \\
\hline $0.05 \mathrm{M}$ ionic strength & 68 \\
0.2 M ionic strength & 64 \\
Bound to CAP & 55 \\
8-times excess Ca ${ }^{2+}(0.4 \mathrm{mM})$ & 66 \\
T21I-mutant & 61 \\
Standard conditions* & $68 *$ \\
\hline
\end{tabular}

*Standard conditions previously reported: $\mathrm{pH}=7.4, \mathrm{IS}=0.15 \mathrm{M}$, and $326 \mu \mathrm{g} / \mathrm{mL}$ LRAP (Lu et al., 2013b). the change in concentration before and after binding and for each wash using ultraviolet absorbance measurements $(\lambda=277)$.

The prepared sample was packed into the NMR rotor by first transferring it to a sealed $1 \mathrm{~mL}$ pipette tip. The tip was centrifuged for $10 \mathrm{~min}$ at $12,000 \mathrm{rpm}$ to remove residual liquid, resulting in a tightly packed hydrated LRAP-HAP/CAP complex. The sealed end was then cut open and the pellet transferred to a $5 \mathrm{~mm}$ NMR rotor using a centrifuge. The rotor was placed in an NMR probe and spun at $6-7 \mathrm{kHz}$ to remove the excess water, resulting in a $>100 \%$ hydrated, surface bound sample. A thin layer of parafilm or a rubber disk was positioned before the rotor's end cap to keep the sample fully hydrated during NMR data collection.

\section{NMR EXPERIMENTS}

All NMR experiments were conducted on a three-channel Chemagnetics Infinity spectrometer (Chemagnetics, Fort Collins, CO) with an Oxford $7.05 \mathrm{~T}\left[\mathrm{v}_{0}\left({ }^{1} \mathrm{H}\right)=300 \mathrm{MHz}\right]$ wide-bore magnet, operating at resonance frequencies of $v_{0}\left({ }^{13} \mathrm{C}\right)=75.78 \mathrm{MHz}$ and $v_{0}\left({ }^{15} \mathrm{~N}\right)=30.54 \mathrm{MHz}$. Deconvolution of the 1D-spectra was performed with Mestranova (Mestrelab Research, Escondido, CA). For chemical shift measurements, a double resonance $\mathrm{HX}$ magic-angle spinning (MAS), variable temperature Chemagnetics probe was used. For REDOR measurements, a triple resonance HXY MAS, variable-temperature Chemagnetics probe was used. Temperatures in the rotor were calibrated using ${ }^{207} \mathrm{~Pb}\left(\mathrm{NO}^{3}\right)_{2}$ (Bielecki and Burum, 1995). Chemical shifts were referenced to the adamantane $\mathrm{CH}$ peak at $40.26 \mathrm{ppm}$ (Wishart et al., 1995), which was referenced to 2,2-dimethyl-2-silapentane-5-sulfonate (DSS).

\section{REDOR}

XY8 phase cycling was applied on both observe $\left({ }^{13} \mathrm{C}\right)$ and dephasing channels $\left({ }^{15} \mathrm{~N}\right.$ or $\left.{ }^{31} \mathrm{P}\right)$ (Gullion and Schaefer, 1989, 1991). For all REDOR experiments, $180^{\circ}$ pulses of $13.0-15.0 \mu \mathrm{s}$ were used for both the observe and dephasing nuclei with a $65 \mathrm{kHz}$ TPPM decoupling field (Bennett et al., 1995) employed during the recoupling and acquisition periods. Both ${ }^{13} \mathrm{C}\left\{{ }^{15} \mathrm{~N}\right\}$ and ${ }^{13} \mathrm{C}\left\{{ }^{31} \mathrm{P}\right\}$ REDOR data were obtained for each sample preparation condition (Table 2). Data were acquired at $-80^{\circ} \mathrm{C}$ to eliminate contributions due to motion and at a spinning speed of $4 \mathrm{kHz}$. For ${ }^{13} \mathrm{C}\left\{{ }^{15} \mathrm{~N}\right\}$ REDOR, dephasing points were collected at 8,24 , 40, 56, 72, 88, and 104 rotor periods. Between 4096 and 8192 scans were taken for 8,24 , and 40 rotor periods, 8192-10240 scans for 56, 72, and 88 rotor periods, and 16384-20480 scans for 104 rotor periods. For ${ }^{13} \mathrm{C}\left\{{ }^{31} \mathrm{P}\right\}$ REDOR, dephasing points were collected at $8,24,40,56,72,88,104$ rotor periods with 4096 scans taken for $8,24,40$, and 56 rotor periods, and 8192-16384 scans for 72,88 , and 104 rotor periods. All data were collected with a $1 \mathrm{~s}$ pulse delay. Each point in the dephasing curve represents the average of at least five repetitions. The REDOR dephasing curves were corrected for the natural abundance background (59 backbone carbonyls and 10 side chain carbonyls, or $41 \%$ of the total signal) and were fit by simulations generated using SIMPSON (Bak et al., 2000). The best fit to the closest distance was determined utilizing a chi-squared analysis to provide a quantitative comparison of any given data set to the calculated dephasing curves. 


\section{RESULTS}

\section{BINDING EFFICIENCY}

As shown in Table 1, LRAP-K24S28 $(+\mathrm{P})$ bound to HAP with similar efficiency under the four conditions varied, where efficiency is the percentage of LRAP bound with respect to the initial amount available. The percent error is estimated based on the binding efficiency of multiple $(>15) \operatorname{LRAP}(+\mathrm{P})$ binding results. Slightly lower binding was observed for the high ionic strength condition and the T21I-mutant. Relative to HAP, LRAP-K24S28 $(+\mathrm{P})$ bound less efficiently to CAP.

\section{CHEMICAL SHIFT STUDIES}

As illustrated in Figure 2 and Table 2, two distinct resonances are observed for the K24 carbonyl resonance in each sample that correspond to two different conformations. As previously described (Lu et al., 2013b), the downfield resonance is most consistent with a helical component of $\mathrm{K} 24$, while the upfield resonance is a combination of a $\beta$-strand component of K24, but also has contributions from the natural abundance (unlabeled) backbone and side chain carbonyls. A random coil component, if present, would be between the two resonances, but due to spectral overlap, we did not try to fit this separately. The chemical shifts of

Table $2 \mid{ }^{13} \mathrm{C}^{\prime}$ chemical shifts for K24 in LRAP-K24S28(+P).

\begin{tabular}{lcc}
\hline $\begin{array}{l}\text { LRAP-K24S28(+P) } \\
\text { binding condition }\end{array}$ & $\begin{array}{c}\text { Chemical shift (ppm) } \\
\text { Downfield resonance } \\
(\boldsymbol{\alpha} \text {-helix })\end{array}$ & $\begin{array}{c}\text { Chemical shift (ppm) } \\
\text { Upfield resonance } \\
(\boldsymbol{\beta} \text {-strand/coil/background) }\end{array}$ \\
\hline Standard conditions & $178.4 \pm 0.5$ & $174.8 \pm 0.5$ \\
IS $=0.05 \mathrm{M}$ & $178.9 \pm 0.5$ & $175.1 \pm 0.5$ \\
IS $=0.2 \mathrm{M}$ & $178.8 \pm 0.5$ & $175.1 \pm 0.5$ \\
8:1 $\mathrm{Ca}^{2+}:[\mathrm{LRAP}]$ & $178.9 \pm 0.5$ & $175.3 \pm 0.5$ \\
Bound to CAP & $178.7 \pm 0.5$ & $175.0 \pm 0.5$ \\
T21I-Mutant & $178.6 \pm 0.5$ & $174.8 \pm 0.5$ \\
\hline
\end{tabular}

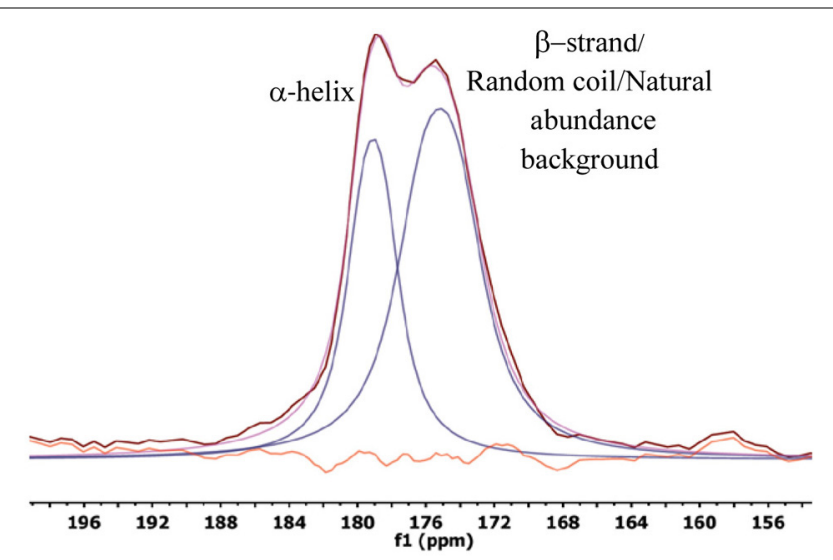

FIGURE 2 | One-dimensional ${ }^{13} \mathbf{C}$ spectrum. Representative spectrum of LRAP-K24S28(+P) bound to HAP, in this case at an ionic strength of $0.05 \mathrm{M}$. The deconvolution is also shown. The data is shown in pink, the combined fit in maroon, with individual fits in blue. The difference of the fit spectrum and the actual spectrum is shown in orange. the helical carbonyl (Table 2) ranged from 178.4 to $178.9 \mathrm{ppm}$, while the upfield carbonyl ranged from 174.8 to $175.3 \mathrm{ppm}$, in both cases invariant within our experimental error to the varying binding conditions.

\section{STRUCTURE AS A FUNCTION OF BINDING CONDITION}

To gain further insight into the structural motif at K24 to S28, the distance between the ${ }^{13} \mathrm{C}$ backbone carbonyl of $\mathrm{K} 24$ and the ${ }^{15} \mathrm{~N}$ amide of S28 was measured for each of the complexes using REDOR (Figure 3). The distances obtained from the resulting dephasing curves are well-established for regular $\alpha$-helices $(4.2 \AA)$ and $\beta$-strands (10.6 $\AA$ ). The dephasing curve for a random coil structure is obtained by averaging all of the dephasing curves between $4.2 \AA$ and $10.6 \AA$, at $0.1 \AA$ intervals, yielding an average distance of $5.8 \AA$. When bound to HAP under standard conditions, LRAP-K24S28 $(+\mathrm{P})$ had a significant helical content based on the ${ }^{13} \mathrm{C}-{ }^{15} \mathrm{~N}$ distance of $4.8 \AA$. As seen in Table 3 , this distance is unchanged when bound at an ionic strength of $0.2 \mathrm{M}$, or for the T21I-mutant bound under standard conditions, indicating a similar content of $\alpha$-helix for these conditions. When bound at an ionic strength of $0.05 \mathrm{M}$, the distance lengthens to $5.2 \AA$ (Figure 3 ), indicating a shift to more random coil structures, and suggesting that salt concentration influences structure. Under conditions where the protein is bound to CAP or bound in the presence of $0.4 \mathrm{mM} \mathrm{Ca}^{2+}$, the distance decreases to $4.4 \AA$ (Figure 3), a value approaching a canonical $\alpha$-helix, suggesting that calcium may stabilize helix formation in this region of LRAP.

The dephasing curves can also result from a combination of multiple distinct structures. In the case of dephasing curves consistent with $\alpha$-helices [e.g., LRAP-K24S28 $(+\mathrm{P})$ bound to CAP or bound to HAP in the presence of $0.4 \mathrm{mM}$ calcium], the contribution from structures other than $\alpha$-helix would be low. However,

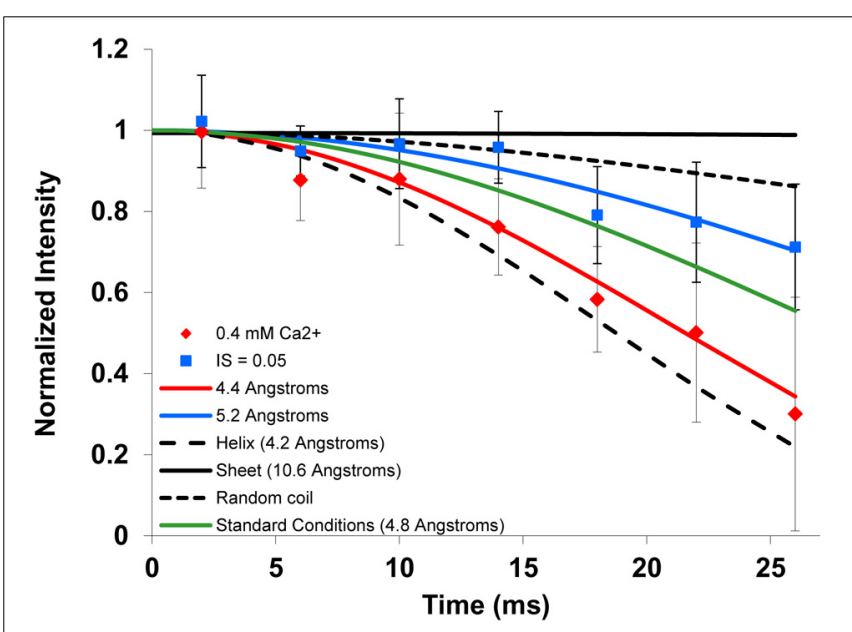

FIGURE 3 | Representative ${ }^{13} \mathrm{C}-{ }^{-15} \mathrm{~N}$ REDOR data and fits. The ${ }^{13} \mathrm{C}-{ }^{15} \mathrm{~N}$ REDOR data shows that LRAP-K24S28(+P) bound to HAP in the presence of excess $\mathrm{Ca}^{2+}$ (red diamonds) had the shortest C-N distance (4.4 $\AA$, nearly helical), while binding at an ionic strength of $0.05 \mathrm{M}$ (blue squares) resulted in a longer C-N distance (5.2 $\AA$ ) consistent with a looser helix or less helical content at low ionic strength. The simulated dephasing curves for an $\alpha$-helix (4.2 $\AA$, dashed), $\beta$-strand (10.6 $\AA$, solid), random coil (long dash), and the standard conditions (green line) are shown for comparison. 
Table 3 | REDOR determined distances for LRAP-K24S28(+P).

\begin{tabular}{|c|c|c|}
\hline $\begin{array}{l}\text { LRAP-K24S28(+P) } \\
\text { binding condition }\end{array}$ & $\begin{array}{c}{ }^{13} \mathrm{C}(i)-{ }^{15} \mathrm{~N}(i+4) \\
\text { distance }\end{array}$ & $\begin{array}{l}{ }^{13} C_{-}{ }^{31 P} \\
\text { distance }\end{array}$ \\
\hline Standard condition & $4.8 \pm 0.4 \AA$ & $7.5 \pm 0.5 \AA$ \\
\hline$I S=0.05 \mathrm{M}$ & $5.2 \pm 0.5 \AA$ & $8.0 \pm 0.5 \AA$ \\
\hline$I S=0.2 \mathrm{M}$ & $4.9 \pm 0.4 \AA$ & $8.0 \pm 0.5 \AA$ \\
\hline 8-times calcium (0.4 mM) & $4.4 \pm 0.3 \AA$ & $8.5 \pm 0.5 \AA$ \\
\hline Bound to CAP & $4.4 \pm 0.3 \AA$ & $7.5 \pm 0.5 \AA$ \\
\hline T21I-Mutant & $4.8 \pm 0.4 \AA$ & $8.5 \pm 0.5 \AA$ \\
\hline
\end{tabular}

for dephasing curves with longer distances which are indicative of structures deviating from a helical structure, contributions from random coil or $\beta$-strand structures can be significant. For example, at an ionic strength of $0.05 \mathrm{M}$, the dephasing curve fits to a single distance of $5.2 \AA$, but could be fit equally well by some contribution of $\alpha$-helix, random coil, and/or $\beta$-strand. To provide a starting point, deconvolution and integration of the 1D-spectra (Figure 2) suggests that $\sim 60 \%$ of this region is in an $\alpha$-helical structure. This number is based on integrations of $37 \% \alpha$-helix (downfield signal) and 23\% other (upfield signal) with the later signal corrected by removing the $40 \%$ intensity contribution due to the natural abundance ${ }^{13} \mathrm{C}^{\prime}$ background. This analysis is not quantitative due to potential errors in deconvoluting as well as other possible contributions to the intensity of the resonance attributed to the $\alpha$-helical component. Fixing the $\alpha$-helical contribution to $60 \%$ resulted in a curve that dephased much faster than the data, regardless of whether the remaining $40 \%$ was random coil or $\beta$-strand. However, a combination of $40 \% \alpha$-helix, $60 \% \beta$-strand fits the data well, as does 30\% $\alpha$-helix, 70\% random coil. These two options cannot be distinguished, nor can they be distinguished from a combination of all three structures $(40 \% \alpha$ helix, $10 \%$ random coil, and $50 \% \beta$-strand) that fit the data. What is clear for the combined chemical shift and REDOR data is that the K24S28 region has a smaller population of $\alpha$-helical character as a function of low ionic strength.

\section{DISTANCE FROM THE SURFACE AS A FUNCTION OF BINDING CONDITION}

The ${ }^{31} \mathrm{P}$ nucleus on the HAP surface provides another handle with which to characterize the HAP-LRAP interface. This is because the distance from the backbone ${ }^{13} \mathrm{C}$ carbonyl to surface ${ }^{31} \mathrm{P}$ can be measured, providing an indication of the orientation of the protein relative to the surface. For instance, if the K24 carbonyl is oriented away from the surface, the ${ }^{13} \mathrm{C}^{3}-{ }^{31} \mathrm{P}$ distance would be long (>12 $\AA$ ), while a strong interaction in this region would result in a much shorter distance. The shortest distance from the backbone ${ }^{13} \mathrm{C}^{\prime}$ observed for LRAP to date is $5.3 \AA$ (Masica et al., 2011).

Binding under standard conditions resulted in a ${ }^{13} \mathrm{C}-{ }^{31} \mathrm{P}$ distance of $7.5 \pm 0.5 \AA$ from the nearest ${ }^{31} \mathrm{P}$ on the surface (Figure 4 and Table 3). Binding to CAP and to HAP at an ionic strength of 0.05 or $0.2 \mathrm{M}$ did not result in any ${ }^{13} \mathrm{C}-{ }^{31} \mathrm{P}$ distance changes relative to the standard condition outside the error limits of the measurements. The largest ${ }^{13} \mathrm{C}-{ }^{31} \mathrm{P}$ distance changes relative to the standard condition were observed for LRAP-K24S28 $(+\mathrm{P})$ in

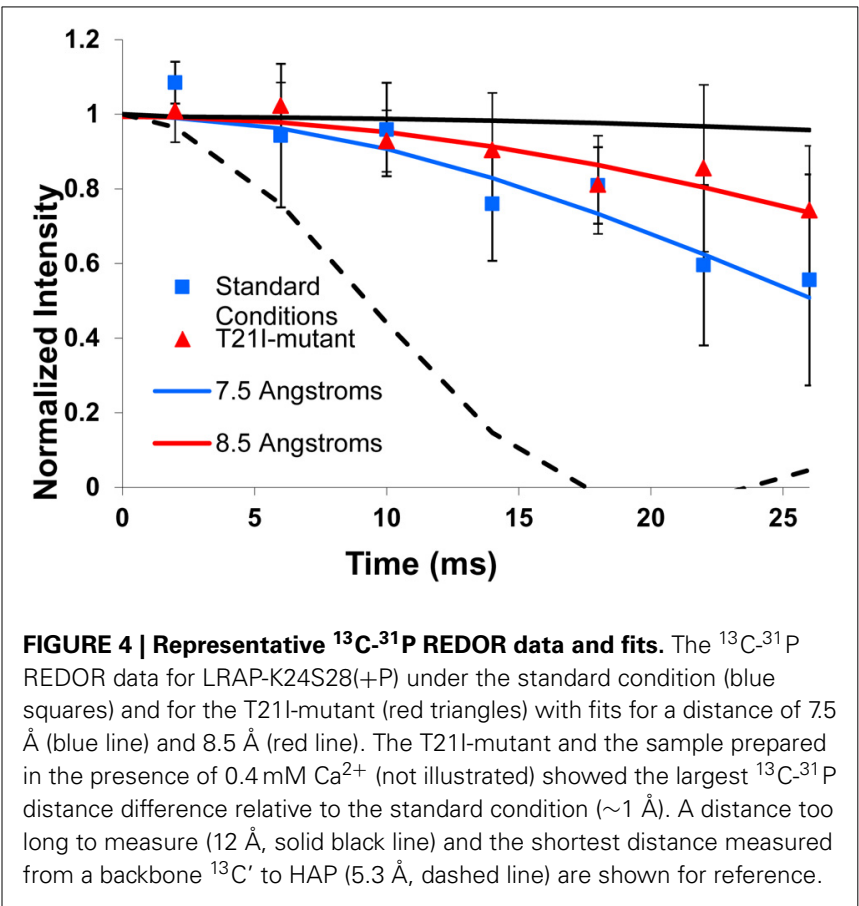

the presence of $0.4 \mathrm{mM} \mathrm{Ca}^{2+}$ and for the T21I-mutant, which both increased to $8.5 \pm 0.5 \AA$ (Figure 4). Interestingly, of the latter two conditions, a change in structure was only observed in the presence of excess calcium.

\section{DISCUSSION}

The amelogenin proteins have been classified as intrinsically disordered (Delak et al., 2009), a characterization which implies structural flexibility may be necessary to achieve a particular function (Tompa, 2002; Uversky, 2002). Consistent with a predilection to structural flexibility, both amelogenin and LRAP are dynamic even when they are bound to HAP (Shaw and Ferris, 2008; Shaw et al., 2008; Masica et al., 2011; Lu et al., 2013a,b). Despite the inherent flexibility, specific structured regions have been identified for the surface immobilized protein based on SSNMR REDOR data (Masica et al., 2011; Lu et al., 2013a,b). The LRAP$\mathrm{K} 24 \mathrm{~S} 28(+\mathrm{P}) /(-\mathrm{P})$ has been identified to be an ideal helix when lyophilized from solution. Upon binding to $\mathrm{HAP}, \operatorname{LRAP}(+\mathrm{P})$ remained helical, while $\operatorname{LRAP}(-\mathrm{P})$ became largely unstructured. The observation of structural lability as a function of phosphorylation suggests an important function for this region of the protein.

Protein structure in solution state NMR is often evaluated using ${ }^{13} \mathrm{C},{ }^{15} \mathrm{~N}$, and ${ }^{1} \mathrm{H}$ chemical shifts. This is because NMR chemical shifts arise from the electron density around the nucleus and differs for each element of secondary structure ( $\alpha$-helix, $\beta$ strand, random coil). For the same reasons, chemical shifts can also provide qualitative insight into the structure of proteins immobilized onto surfaces in the solid state. In this case, the unique observation of two resonances for the carbonyl of K24 compared to one resonance for all of the other carbonyls studied for LRAP (Shaw et al., 2004, 2008; Shaw and Ferris, 2008; Masica et al., 2011; Lu et al., 2013a,b) suggests a unique and 
important structural feature for this region of the protein. We previously demonstrated that the downfield K24 carbonyl resonance is most consistent with an $\alpha$-helical conformation, based on the downfield chemical shift expected for a helical carbonyl and the evaluation of REDOR data for this resonance alone ( $\mathrm{Lu}$ et al., 2013b). That two K24 carbonyl resonances are observed under each of the preparation conditions tested (Table 2) suggests that there are common structural features, including a significant amount of helical structure at K24, regardless of the preparation.

In addition to secondary structure, for surface immobilized proteins, differences in chemical shift can also arise from how the protein is associated with the highly charged surface due to alterations of local electron density. Consequently, the chemical shift and intensity measurements for the two K24 carbonyl resonances are qualitative and the interpretations need to be treated with care. The difficulty in quantifying chemical shift information for surface immobilized proteins due to these two contributions emphasizes the need for a more quantitative technique. Dipolar recoupling techniques such as REDOR, which directly measure the distance between two nuclei, provide such quantitation.

The REDOR data under the binding conditions studied here provide further evidence for a structurally flexible region centered around the K24S28 region that may play a functional role. For example, the REDOR data is consistent with an ideal $\alpha$-helix in this region in the presence of excess $\mathrm{Ca}^{2+}\left(8: 1\left[\mathrm{Ca}^{2+}\right]:[\right.$ LRAP$\mathrm{K} 24 \mathrm{~S} 28(+\mathrm{P})]$ ), suggesting a significant increase in helical content in this region relative to binding under the standard condition. Associated with this increase in helical character is a $1 \AA$ increase in the K24 carbonyl distance to ${ }^{31} \mathrm{P}$ on the surface. Since soluble free calcium is present in vivo in the enamel fluid at similar concentrations to those used in our studies (Aoba and Moreno, 1987), this is a critical observation and suggests the importance of calcium in dictating structure. Previously, small angle X-ray scattering was used to investigate the overall shape of $\operatorname{LRAP}(+\mathrm{P})$ and $\operatorname{LRAP}(-\mathrm{P})$ in solution as a function of $\mathrm{Ca}^{2+}$ concentration. Under $\mathrm{Ca}^{2+}$ :[LRAP] ratios similar to ours, significant structural changes were also observed with $\operatorname{LRAP}(+\mathrm{P})$ transitioning from an extended to a more globular structure as a function of increasing $\mathrm{Ca}^{2+}$ (Le Norcy et al., 2011a). While the X-ray scattering and sedimentation experiments do not have the resolution to identify molecular level structural changes, the microscopic changes observed here using SSNMR are in agreement with the macroscopic changes observed using sedimentation velocity and X-ray scattering and may be providing the first insight into the reasons behind the macroscopic changes. Further comparisons suggest a competition between solubilized calcium and calcium in the HAP lattice that impact structure: LRAP-K24S28 $(+\mathrm{P})$ had a distance consistent with an ideal helix (measured distance was $4.2 \pm$ $0.3 \AA$ ) when lyophilized from solution with $0.007 \mathrm{mM} \mathrm{Ca}^{2+}$ in solution. When LRAP-K24S28(+P) was bound to HAP, a loss of helical structure was observed unless excess solution calcium $\left(0.4 \mathrm{mM} \mathrm{Ca}^{2+}\right)$ was present. These observations suggest that the structural changes resulting from binding solution calcium modify the protein:surface interface. Given the observed structural change, a reasonable expectation would be different surface coverages in the presence or absence of $\mathrm{Ca}^{2+}$, however, similar surface coverage by the protein was obtained. Since the observed structural change does not control the amount of protein binding, the structural change resulting from excess solution $\mathrm{Ca}^{2+}$ must serve another function, such as activating protein binding or mineral growth. Indeed, protein-protein interactions were observed to increase for $\operatorname{LRAP}(+\mathrm{P})$ in solution in the presence of excess solution $\mathrm{Ca}^{2+}$ (Le Norcy et al., 2011a), and these interactions may play an important role for the surface immobilized protein.

Although the majority of studies of amelogenin interactions with crystal surfaces have involved HAP (Moradian-Oldak et al., 1998a,b, 2002; Habelitz et al., 2006; Wang et al., 2007; Shaw and Ferris, 2008; Shaw et al., 2008; Kwak et al., 2009, 2011; Tarasevich et al., 2009; Le Norcy et al., 2011a,b; Masica et al., 2011; Uskokovic et al., 2011; Lu et al., 2013a,b), CAP is a more direct analog of enamel (Simmer and Fincham, 1995; Fincham et al., 1999; Margolis et al., 2006). The structure at LRAP-K24S28(+P) is also consistent with an ideal $\alpha$-helix when bound to CAP $(4.4 \pm 0.3 \AA)$, in contrast to HAP where the structure is shifted toward random coil $(4.8 \pm 0.4 \AA)$. This is some of the first data suggesting that carbonation influences the structure of amelogenins, and therefore, could influence the resulting mineral growth.

The T21I-mutant is one of many naturally occurring, singlesite mutations found in full-length amelogenin that results in enamel hypoplasia, with enamel features including smooth pits, variable thickness, mottled, and brown color (Ravassipour et al., 2000). That this significant loss of functional enamel results from a single-site mutation strongly suggests a change in structure, and changes in tertiary structure (protein-protein interactions) have been observed (Moradian-Oldak et al., 2000; Paine et al., 2002; Buchko et al., 2013). However, no structural change for the T21I-mutant was observed in LRAP-K24S28 $(+\mathrm{P})$, despite the proximity of the mutated residue to the $\mathrm{K} 24 \mathrm{~S} 28$ region. The mutation did result in the region being further from the surface and a simple interpretation for this observation is that the threonine in the native protein assists in holding the protein closer to the surface and replacement with a hydrophobic isoleucine destabilized this interaction. The distance from the surface for the T21I-mutation determined under standard conditions is similar to that found when excess $\mathrm{Ca}^{2+}$ was present, though it is unclear at this time if there is a mechanistic correlation between these two observations.

The functional importance of the structural flexibility in the K24S28 region is not clear and further crystal growth and structural studies will be necessary to tease out the mechanistic details. An equally important observation is that the structure doesn't completely switch conformations, i.e., under all conditions studied, there is still some helical character. This could merely be a result of the high entropic costs associated with switching structures when the protein is immobilized. Given the uniqueness of this structured region in LRAP, a more likely explanation is that it is a critical part of the functional design, possibly serving a regulatory role in enamel development. Only the continued in vitro investigation of the structural and functional properties of the amelogenin proteins will allow us to fully explore these mechanisms. 


\section{SUMMARY}

The $\operatorname{LRAP}(+\mathrm{P})$ :HAP interaction of the structurally flexible K24S28 region was evaluated as a function of ionic strength, calcium concentration, surface type, and protein mutation. Modest differences were observed in both structure and distance from the surface for this region of the protein. The most significant difference, relative to the standard condition, was observed with LRAP bound to HAP in the presence of excess $\mathrm{Ca}^{2+}$, where the protein in this region transitioned from a looser $\alpha$-helix to a nearly ideal $\alpha$-helical structure and moved further from the surface. The dependence of LRAP structure (secondary, tertiary) on calcium concentration is mounting, and these studies have provided some of the first insights at the molecular level. Using a CAP surface also resulted in a more ideal helical structure, while the T21I-mutation resulted in moving the K24S28 region further from the surface. Collectively, these data provide continued evidence of the structural flexibility of the K24S28 region in amelogenins and further implicated it as a functionally important region.

\section{ACKNOWLEDGMENTS}

The authors thank Dr. Claude Yoder (Franklin and Marshall College) for supplying the carbonated apatite. This research was supported by NIH-NIDCR Grant DE-015347. The research was performed at the Pacific Northwest National Laboratory (PNNL), a facility operated by Battelle for the US Department of Energy.

\section{REFERENCES}

Aoba, T., and Moreno, E. C. (1987). The enamel fluid in the early secretory stage of porcine amelogenesis: chemical composition and saturation with respect to enamel mineral. Calcif. Tissue Int. 41, 86-94. doi: 10.1007/BF02555250

Bak, M., Rasmussen, J. T., and Nielsen, N. C. (2000). SIMPSON: a general simulation program for solid-state NMR spectroscopy. J. Magn. Res. 147, 296-330. doi: 10.1006/jmre.2000.2179

Bennett, A. E., Rienstra, C. M., Auger, M., Lakshmi, K. V., and Griffin, R. G. (1995). Heteronuclear decoupling in rotating solids. J. Chem. Phys. 103, 6951-6958. doi: $10.1063 / 1.470372$

Bielecki, A., and Burum, D. P. (1995). Temperature-dependence of Pb-207 MAS spectra of solid lead nitrate - an accurate, sensitive thermometer for variabletemperature MAS. J. Magn. Res. A 116, 215-220. doi: 10.1006/jmra.1995.0010

Buchko, G. W., Lin, G., Tarsevich, B. J., and Shaw, W. J. (2013). A solution NMR investigation into the impaired self-assembly properties of two murine amelogenins containing the point mutations T21I or P41T. Arch. Biochem. Biophys. 537, 217-224. doi: 10.1016/j.abb.2013.07.015

Carpino, L. A., and Han, G. Y. (1972). 9-Fluorenylmethoxycarbonyl aminoprotecting group. J. Organ. Chem. 37, 3404-3409. doi: 10.1021/jo00795a005

Delak, K., Harcup, C., Lakshminarayanan, R., Sun, Z., Fan, Y. W., MoradianOldak, J., et al. (2009). The tooth enamel protein, porcine amelogenin, is an intrinsically disordered protein with an extended molecular configuration in the monomeric form. Biochemistry 48, 2272-2281. doi: 10.1021/bi802175a

Drobny, G. P., Long, J. R., Karlsson, T., Shaw, W. J., Popham, J., Oyler, N., et al. (2003). Structural studies of biomaterials using double quantum solid state NMR spectroscopy. Annu. Rev. Phys. Chem. 54, 531-571. doi: 10.1146/annurev.physchem.54.011002.103903

Drobny, G. P., Long, J. R., Shaw, W. J., Cotten, M., and Stayton, P. S. (2002). Structure and dynamics of proteins adsorbed to biomaterial interfaces. Encyclop. Nucl. Magn. Res. 9, 458-468. doi: 10.1002/9780470034590.emrstm0540

Drobny, G. P., Stayton, P. S., Long, J. R., Louie, E. A., Karlsson, T., Popham, J. M., et al. (2006). "NMR Spectroscopy of Biological Solids," in Structural Studies of Peptides on Biomaterial Surfaces Using Double-Quantum Solid-State Nuclear Magnetic Resonance Spectroscopy, ed A. Ramamoorthy (New York, NY: CRC/Taylor \& Francis Group).

Ebrahimpour, A., Johnsson, M., Richardson, C. F., and Nancollas, G. H. (1993). The characterization of hydroxyapatite preparations. J. Coll. Int. Sci. 159, 158-163. doi: 10.1006/jcis.1993.1307
Fincham, A. G., Moradian-Oldak, J., and Simmer, J. P. (1999). The structural biology of the developing dental enamel matrix. J. Struct. Biol. 136, 270-299.

Fincham, A. G., Moradian-Oldak, J., Simmer, J. P., Sarte, P., Lau, E. C., Diekwisch, T., et al. (1994). Self-assembly of a recombinant amelogenin protein generates supramolecular structures. J. Struct. Biol. 112, 103-109. doi: 10.1006/jsbi.1994.1011

Gibson, C. W., Golub, E., Ding, W. D., Shimokawa, H., Young, M., Termine, J., et al. (1991). Identification of the leucine-rich amelogenin peptide (LRAP) as the translation product of an alternatively spliced transcript. Biochem. Biophys. Res. Commun. 174, 1306-1312. doi: 10.1016/0006-291X(91)91564-S

Gibson, C. W., Li, Y., Daly, B., Suggs, C., Yuan, Z.-A., Fong, H., et al. (2008). The leucine-rich amelogenin peptide alters the amelogenin null enamel phenotype. Cells Tissues Organs 189, 169-174. doi: 10.1159/000151384

Goobes, G., Goobes, R., Shaw, W. J., Gibson, J. M., Long, J. R., Raghunathan, V., et al. (2007). The structure, dynamics and energetics of protein adsorptionlessons learned from adsorption of statherin to hydroxyapatite. Magn. Res. Chem. 45(Suppl.), S32-S47. doi: 10.1002/mrc.2123

Gullion, T., and Schaefer, J. (1989). Rotational-echo double-resonance NMR. J. Magn. Res. 81, 196-200.

Gullion, T., and Schaefer, J. (1991). Elimination of resonance offset effects in rotational-echo, double-resonance NMR. J. Magn. Res. 92, 439-442.

Habelitz, S., DenBesten, P. K., Marshall, S. J., Marshall, G. W., and Li, W. (2006). Self-assembly and effect on crystal growth of the leucine-rich amelogenin peptide. Eur. J. Oral Sci. 114, 315-319. doi: 10.1111/j.1600-0722.2006.00312.x

Kwak, S. Y., Green, S., Wiedemann-Bidlack, F. B., Beniash, E., Yamakoshi, Y., Simmer, J. P., et al. (2011). Regulation of calcium phosphate formation by amelogenins under physiological conditions. Eur. J. Oral Sci. 119(Suppl. 1), 103-111. doi: 10.1111/j.1600-0722.2011.00911.x

Kwak, S.-Y., Wiedemann-Bidlack, R. B., Beniash, E., Yamakoshi, Y., Simmer, J. P., Litman, A., et al. (2009). Role of 20-kDa amelogenin (P148) phosphorylation in calcium phosphate formation in vitro. J. Biol. Chem. 284, 18972-18979. doi: 10.1074/jbc.M109.020370

Le Norcy, E., Kwak, S. Y., Allaire, M., Fratzl, P., Yamakoshi, Y., Simmer, J. P., et al. (2011a). Effect of phosphorylation on the interaction of calcium with leucine-rich amelogenin peptide. Eur. J. Oral Sci. 119(Suppl. 1), 97-102. doi: 10.1111/j.1600-0722.2011.00900.x

Le Norcy, E., Kwak, S. Y., Wiedemann-Bidlack, F. B., Beniash, E., Yamakoshi, Y., Simmer, J. P., et al. (2011b). Leucine-rich amelogenin peptides regulate mineralization in vitro. J. Dent. Res. 90, 1091-1097. doi: 10.1177/0022034511411301

Le Norcy, E., Kwak, S. Y., Wiedemann-Bidlack, F. B., Beniash, E., Yamakoshi, Y., Simmer, J. P., et al. (2011c). Potential role of the amelogenin N-terminus in the regulation of calcium phosphate formation in vitro. Cells Tissues Organs 194, 188-193. doi: 10.1159/000324827

Le, T. Q., Gochin, M., Featherstone, J. D., Li, W., and DenBesten, P. K. (2006). Comparative calcium binding of leucine-rich amelogenin peptide and fulllength amelogenin. Eur. J. Oral Sci. 114(Suppl. 1), 320-326. discussion: 327-329, 382. doi: 10.1111/j.1600-0722.2006.00313.x

Lu, J.-X., Xu, Y. S., Buchko, G. W., and Shaw, W. J. (2013a). Mineral association changes the secondary structure and dynamics of murine amelogenin. J. Dent. Res. 92, 1000-1004. doi: 10.1177/0022034513504929

Lu, J.-X., Xu, Y. S., and Shaw, W. J. (2013b). Phosphorylation and ionic strength alter the LRAP-HAP interface in the N-terminus. Biochemistry 52, 2196-2205. doi: 10.1021/bi400071a

Margolis, H. C., Beniash, E., and Fowler, C. E. (2006). Role of macromolecular assembly of enamel matrix proteins in enamel formation. J. Dent. Res. 85, 775-793. doi: 10.1177/154405910608500902

Masica, D. L., Gray, J. J., and Shaw, W. J. (2011). Partial high-resolution structure of phosphorylated and non-phosphorylated leucine-rich amelogenin protein adsorbed to hydroxyapatite. J. Phys. Chem. C 115, 13775-13785. doi: $10.1021 /$ jp202965h

Moradian-Oldak, J. (2001). Amelogenins: assembly, processing and control of crystal morphology. Matrix Biol. 20, 293-305. doi: 10.1016/S0945-053X(01) 00154-8

Moradian-Oldak, J., Bouropoulos, N., Wang, L., and Gharakhanian, N. (2002). Analysis of self-assembly and apatite binding properties of amelogenin protein lacking the hydrophilic C-terminal. Matrix Biol. 21, 197-205. doi: 10.1016/S0945-053X(01)00190-1

Moradian-Oldak, J., Leung, W., Tan, J., and Fincham, A. G. (1998a). Effect of apatite crystals on the activity of amelogenin degrading enzymes in vitro. Connect. Tissue Res. 39, 131-140; discussion: 141-139. 
Moradian-Oldak, J., Tan, J., and Fincham, A. G. (1998b). Interaction of amelogenin with hydroxyapatite crystals: an adherence effect through amelogenin molecular self-association. Biopolymers 46, 225-238.

Moradian-Oldak, J., Paine, M. L., Lei, Y. P., Fincham, A. G., and Snead, M. L. (2000). Self-assembly properties of recombinant engineered amelogenin proteins analyzed by dynamic light scattering and atomic force microscopy. J. Struct. Biol. 131, 27-37. doi: 10.1006/jsbi.2000.4237

Moradian-Oldak, J., Simmer, J. P., Lau, E. C., Diekwisch, T., Slavkin, H. C., and Fincham, A. G. (1995). A review of the aggregation properties of a recombinant amelogenin. Connect. Tissue Res. 32, 125-130.

Moradian-Oldak, J., Simmer, J. P., Lau, E. C., Sarte, P. E., Slavkin, H. C., and Fincham, A. G. (1994). Detection of monodisperse aggregates of a recombinant amelogenin by dynamic light-scattering. Biopolymers 34, 1339-1347. doi: 10.1002/bip.360341006

Paine, M. L., Lei, P.-Y., Dickerson, K., and Snead, M. L. (2002). Altered amelogenin self-assembly based on mutations observed in human X-linked amelogeninsis imperfacta (AIH1). J. Biol. Chem. 277, 17112-17116. doi: 10.1074/jbc.M110473200

Ravassipour, D. B., Hart, P. S., Hart, T. C., Ritter, A. V., Yamauchi, M., Gibson, C., et al. (2000). Unique enamel phenotype associated with amelogenin gene (AMELX) codon 41 point mutation. J. Dent. Res. 79, 1476-1481. doi: 10.1177/00220345000790070801

Ravindranath, R. M. H., Devarajan, A., and Bringas, P. Jr. (2007). Enamel formation in vitro in mouse molar explants exposed to amelogenin polypeptides ATMP and LRAP on enamel development. Arch. Oral Biol. 52, 1161-1171. doi: 10.1016/j.archoralbio.2007.06.008

Shaw, W. J., Campbell, A. A., Paine, M. L., and Snead, M. L. (2004). The COOH terminus of the amelogenin, LRAP, is oriented next to the hydroxyapatite surface. J. Biol. Chem. 279, 40263-40266. doi: 10.1074/jbc.C400322200

Shaw, W. J., and Ferris, K. (2008). Structure, orientation, and dynamics of the C-terminal hexapeptide of LRAP determined using solid-state NMR. J. Phys. Chem. B 112, 16975-16981. doi: 10.1021/jp808012g

Shaw, W. J., Ferris, K., Tarasevich, B., and Larson, J. L. (2008). The structure and orientation of the C-terminus of LRAP. Biophys. J. 94, 3247-3257. doi: 10.1529/biophysj.107.119636

Simmer, J. P., and Fincham, A. G. (1995). Molecular mechanisms of dental enamel formation. Crit. Rev. Oral Biol. Med. 6, 84-108. doi: 10.1177/10454411950060020701

Stahl, J., Nakano, Y., Kim, S.-O., Gibson, C. W., Le, T., and DenBesten, P. (2013). Leucine rich amelogenin peptide alters ameloblast differentiation in vivo. Matrix Biol. 32, 432-442. doi: 10.1016/j.matbio.2013.05.004

Stayton, P., Drobny, G., Shaw, W., Long, J., and Gilbert, M. (2003). Molecular recognition at the protein-hydroxyapatite interface. Crit. Rev. Oral Biol. Med. 15, 370-376. doi: 10.1177/154411130301400507

Tarasevich, B. J., Lea, S., Bernt, W., Engelhard, M., and Shaw, W. J. (2009). Adsorption of amelogenin onto self-assembled and fluoroapatite surfaces. J. Phys. Chem. B 113, 1833-1842. doi: 10.1021/jp804548x
Tarasevich, B. J., Lea, S., and Shaw, W. J. (2010). The leucine rich amelogenin protein (LRAP) adsorbs as monomers or dimers onto surfaces. J. Struct. Biol. 169, 266-276. doi: 10.1016/j.jsb.2009.10.007

Tarasevich, B. J., Perez-Salas, U., Masica, D. L., Philo, J., Kienzle, P., Krueger, S., et al. (2013). Neutron reflectometry studies of the adsorbed structure of the amelogenin, LRAP. J. Phys. Chem. B 117, 3098-3109. doi: 10.1021/ jp311936j

Tompa, P. (2002). Instrinsically unstructured proteins. Trends Biochem. Sci. 27. 527-533. doi: 10.1016/S0968-0004(02)02169-2

Uskokovic, V., Li, W., and Habelitz, S. (2011). Amelogenin as a promoter of nucleation and crystal growth of apatite. J. Cryst. Growth 316, 106-117. doi: 10.1016/j.jcrysgro.2010.12.005

Uversky, V. N. (2002). Natively unfolded proteins: a point where biology waits for physics. Protein Sci. 11, 739-756. doi: 10.1110/ps.4210102

Wang, L. J., Guan, X. Y., Du, C., Moradian-Oldak, J., and Nancollas, G. H. (2007). Amelogenin promotes the formation of elongated apatite microstructures in a controlled crystallization system. J. Phys. Chem. C 111, 6398-6404. doi: 10.1021/jp0675429

Wiejak, S., Masiukiewicz, E., and Rzeszotarska, B. (1999). A large scale synthesis of mono- and di-urethane derivatives of lysine. Chem. Pharm. Bull. 47, 1489-1490. doi: $10.1248 /$ cpb.47.1489

Wishart, D. S., Bigam, C. G., Yao, J., Abildgaard, F., Dyson, H. J., Oldfield, E., et al. (1995). H-1, C-13 and N-15 chemical-shift referencing in biomolecular NMR. J. Biomol. NMR 6, 135-140. doi: 10.1007/BF00211777

Zhang, X., Ramirez, B. E., Liao, X., and Diekwisch, T. G. H. (2011). Amelogenin supramolecular assembly in nanospheres defined by a complex helix-coilPPII helix 3D-structure. PLoS ONE 6:e24952. doi: 10.1371/journal.pone. 0024952

Conflict of Interest Statement: The authors declare that the research was conducted in the absence of any commercial or financial relationships that could be construed as a potential conflict of interest.

Received: 17 May 2014; paper pending published: 02 June 2014; accepted: 17 June 2014; published online: 11 July 2014.

Citation: Lu J-x, Burton SD, Xu YS, Buchko GW and Shaw WJ (2014) The flexible structure of the K24S28 region of Leucine-Rich Amelogenin Protein (LRAP) bound to apatites as a function of surface type, calcium, mutation, and ionic strength. Front. Physiol. 5:254. doi: 10.3389/fphys.2014.00254

This article was submitted to Craniofacial Biology, a section of the journal Frontiers in Physiology.

Copyright (c) $2014 \mathrm{Lu}$, Burton, Xu, Buchko and Shaw. This is an open-access article distributed under the terms of the Creative Commons Attribution License (CC BY). The use, distribution or reproduction in other forums is permitted, provided the original author(s) or licensor are credited and that the original publication in this journal is cited, in accordance with accepted academic practice. No use, distribution or reproduction is permitted which does not comply with these terms. 